\title{
Distribuição das ceratites infecciosas em hospital terciário no Brasil
}

\section{Distribution of infectious keratitis in a tertiary hospital in Brazil}

Fábio Iglesias Marujo ${ }^{1}$, Flávio Eduardo Hiral ${ }^{2}$, Maria Cecília Zorat Yu³, Ana luisa Hofling-Lima², Denise de Freitas², Elcio Hideo Sato²

\section{RESUMO}

Objetivo: Investigar sazonalidade de ceratities infecciosas em serviço terciário no Brasil.

Métodos: Estudo retrospectivo de dados coletados do Laboratório de Microbiologia Ocular do Departamento de Oftalmologia da Universidade Federal de São Paulo de 2005 a 2009. Foram definidas como ceratites infecciosas aquelas com cultura positiva para o agente. Dados foram distribuídos de acordo com os meses do ano e modelos de regressão linear com variáveis"dummy"foram utilizados para testar sazonalidade.

Resultados: Foram diagnosticados 1.468 casos de ceratite infecciosa durante o período do estudo. Bactérias foram responsáveis por $80,3 \%$ dos casos seguidas por fungos (7\%), Acanthamoeba (6\%) e casos mistos (6,7\%). Testes estatísticos não mostraram sazonalidade para bactérias $(p=0,064)$, fungos $(p=0,379)$, Acanthamoeba ( $p=0,062)$ ou casos mistos $(p=0,441)$.

Conclusão: Não foi observada sazonalidade nas ceratites infecciosas em nossa amostra.

Descritores: Ceratite; Córnea; Úlcera de córnea; Infecções oculares bacterianas/ microbiologia; Infecções oculares fúngicas/microbiologia

\begin{abstract}
Purpose: To investigate the seasonality of infectious keratitis in a tertiary hospital in Brazil.

Methods: Charts from the Ocular Microbiology Laboratory of the Department of Ophthalmology of the Federal University of Sao Paulo were reviewed from 2005 to 2009. Infectious keratitis were defined as those with positive culture. Data were distributed monthly and linear regressions with seasonal dummy models were used to test for seasonal trends.

Results: Total of 1,468 cases of keratitis was diagnosed during the study period. Bacterial keratitis were reponsible for $80.3 \%$ of all cases, followed by fungal (7\%), and Acanthamoeba (6\%); $6.7 \%$ were mixed cases. Statistical tests showed that there were no seasonal trends for bacteria $(p=0.064)$, fungi $(p=0.379)$, Acanthamoeba $(p=0.062)$ or mixed infections ( $p=0.441$ ).
\end{abstract}

Conclusions: No seasonal trends for infectious keratitis were observed in our sample. Keywords: Keratitis; Cornea; Cornealulcer; Eye infections, bacterial/microbiology; Eye infections, fungal/microbiology

\section{INTRODUÇÃO}

Ceratites infecciosas são uma das maiores causas de deficiência visual em todo o mundo e o diagnóstico e tratamento precoce dessas doenças são essenciais para prevenção de possíveis complicações, como endoftalmite ou perda da visão. Muitos micro-organismos podem causar úlceras de córnea, como bactérias, fungos, protozoários e vírus ${ }^{(1,2)}$

Ceratite apresenta incidência maior nos países em desenvolvimento (299:100000)(3) do que nos desenvolvidos, como nos Estados Unidos da América (11:100000)(4). Essa diferença regional é consequência, principalmente, da frequência dos fatores de risco em cada população. Em países em desenvolvimento, trauma ocular tem sido responsável por 48 a 65\% dos casos de úlcera de córnea ${ }^{(3)}$, enquanto nos EUA, um dos principais fatores de risco é uso de lentes de contato, com $52 \%{ }^{(5)}$, sendo trauma ocular responsável por $27 \%$ dos $\operatorname{casos}^{(4)}$.

Sazonalidade das ceratites infecciosas é pouco estudada. Pesquisa recente realizada na Índia mostrou que houve aumento de casos de ceratite fúngica nos meses de maior umidade que coincidiu também com o período de colheitas na zona rural. Tal padrão de sazonalidade foi observado durante três anos consecutivos ${ }^{(6)}$. Ibrahim et al. estudaram a sazonalidade de ceratites fúngicas no Brasil através da venda de colírios antifúngicos. Os autores observaram relação do aumento de vendas de antifúngicos nos meses de menor umidade do $\operatorname{ar}^{(7)}$. A determinação da sazonalidade permitiria, por exemplo, desenvolvimento de ações preventivas contra essa doença, que pode ser extremamente debilitante.

O Departamento de Oftalmologia da Universidade Federal de São Paulo (UNIFESP) é um serviço de atendimento terciário e considerado como centro de referência para diversas doenças oculares, assim como o Laboratório de Microbiologia Ocular da UNIFESP que também é referência no auxílio diagnóstico de infecções oculares servindo a comunidade oftalmólogica ${ }^{(8)}$. Coleta sistemática de dados padronizados permite avaliação de séries históricas sobre agentes das principais infecções oculares.

O objetivo do estudo é de caracterizar a distribuição sazonal dos casos de ceratite infecciosa detectados no Laboratório de Microbio-
Submetido para publicação: 21 de março de 2013 Aceito para publicação: 15 de julho de 2013

Trabalho realizado na Universidade Federal de São Paulo - UNIFESP - São Paulo (SP), Brasil.

Acadêmico, Curso de Medicina da Escola Paulista de Medicina, Universidade Federal de São Paulo - UNIFESP - São Paulo (SP), Brasil.

${ }_{2}$ Médico(a), Departamento de Oftalmologia, Universidade Federal de São Paulo - UNIFESP - São 2 Médico(a), Departame
Paulo (SP), Brasil.

Biomédica, Laboratório de Microbiologia Ocular, Universidade Federal de São Paulo - UNIFESP . São Paulo (SP), Brasil.
Financiamento: Fábio I. Marujo foi bolsista de iniciação científica (PIBIC) do CNPq.

Divulgação de potenciais conflitos de interesse: F.I.Marujo, Nenhum; F.E.Hirai, Nenhum; M.C.Z.Yu, Nenhum; A.L.Hofling-Lima, Nenhum; D.Freitas, Nenhum; E.H.Sato, Nenhum.

Endereço para correspondência: Flavio E. Hirai. Departamento de Oftalmologia. Rua Botucatu, 821 - São Paulo (SP) - 04023-062 - Brasil - E-mail: fhirai@yahoo.com 
logia Ocular do Departamento de Oftalmologia da UNIFESP durante um período de 5 anos (2005 a 2009).

\section{MÉTODOS}

Estudo retrospectivo, com coleta de dados do Laboratório de Microbiologia Ocular do Departamento de Oftalmologia da UNIFESP. Após análise de resultados de exames de microbiologia realizados a partir de materiais ou tecidos de pacientes com suspeita clínica de ceratite infecciosa de 2005 a 2009, foram consideradas todas as ceratites causadas por bactérias, fungos e Acanthamoeba. Só foram considerados como ceratites infecciosas para pesquisa os casos de ceratite cuja cultura tenha sido positiva para ao menos um desses três grupos de agentes. Dados como agente causador, dados demográficos (nome, sexo, idade do paciente) e data da coleta do exame foram coletados.

Foi realizada comparação de dados estratificados por meses, mostrando a sazonalidade (variabilidade temporal do número de casos) do total de ceratites infecciosas e por cada agente específico, ao longo do ano. Para testar se houve tendência sazonal na amostra, foi construído um modelo de regressão linear com variáveis "dummy" ("seasonal dummy model") e o valor de $p<0,05$ foi considerado estatisticamente significante. Toda análise foi realizada com programa Stata v.11 (College Station, Texas, EUA).

Este estudo foi aprovado pelo Comitê de Ética em Pesquisa UNIFESP (1852/10).

\section{RESULTADOS}

Foram analisados 2.049 casos clinicamente suspeitos de ceratite infecciosa de 2005 a 2009. A população estudada era composta por $45 \%$ do sexo feminino e 55\% do masculino, com idade média de 45 anos sendo que $50 \%$ encontravam-se na faixa etária entre 20 e 59 anos.

De todos os casos, $1.468(71,6 \%)$ apresentaram cultura positiva para ao menos um agente infeccioso (fungos, bactérias ou Acanthamoeba) e foram incluídos na análise de sazonalidade.

Tabela 1 mostra o número de casos de ceratite em cada mês. A figura 1 mostra a proporção de cada agente dentre todos os casos no período estudado. A maior parte dos casos de ceratite, em qualquer época do ano foi bacteriana, sendo responsável por $80,3 \%$ de todos os casos nos cinco anos analisados. Em segundo lugar, ficaram as ceratites fúngicas, com 7,0\%, seguida da ceratite por Acanthamoeba, com 6,0\% dos casos. Também houve casos de infecções mistas, por mais de um agente, sendo mais frequentes as associações de Acanthamoeba com bactéria (4,0\%) e fungo com bactéria (3,0\%).

Dentre os agentes encontrados (Tabela 2), o mais frequente foi - Staphylococcus (presente em 770 casos, 52\% do total de bactérias e $38 \%$ do total geral), especialmente os Staphylococcus coagulase negativos (crescendo em 624 culturas, 42\% do total de bactérias e $30 \%$ do total geral), seguidos pelo S. aureus (com 145 culturas, 10\% do total de bactérias e $7 \%$ do total geral). 0 segundo agente mais encontrado foram as bactérias do gênero Corynebacterium (em 210 casos, $14 \%$ das bactérias e $10 \%$ do total geral). Streptococcus ficaram em terceiro lugar (em 148 culturas, 10\% das bactérias e $7 \%$ do total geral), sendo quase que exclusivamente Streptococcus $\alpha$-hemolíticos.

Considerando apenas os fungos, os filamentosos (em 116 culturas, $6 \%$ do total geral) foram mais frequentemente encontrados do que os leveduriformes (em 33 casos, 2\% do total geral). Fusarium destaca-se entre os filamentosos (com 68 culturas, $60 \%$ dos fungos filamentosos e $3 \%$ do total geral), enquanto a Candida predomina dentre os leveduriformes (com 31 casos, 94\% das leveduras e $2 \%$ do total geral).

Observa-se, na figura 2, picos de frequência para ceratites bacterianas nos meses de maio e setembro. Entretanto, não foi observada uma heterogeneidade muito expressiva entre os meses do ano em relação à variação sazonal das infecções bacterianas sendo o teste estatístico de sazonalidade $(p=0,064)$ não significante.

Figura 3 mostra distribuição das ceratites não bacterianas. Observa-se também alguns picos em alguns meses, mas, que não caracterizam sazonalidade ( $p=0,379$ para fungos; $p=0,062$ para Acanthamoeba; $p=0,441$ para fungo + bactéria e $p=0,451$ para bactéria + Acanthamoeba). Vale ressaltar que as variações apresentadas no gráfico ocorrem em um número pequeno de casos.

\section{DISCUSSÃO}

O valor de positividade das culturas e distribuição dos principais agentes concordam com dados publicados na literatura(9,10).

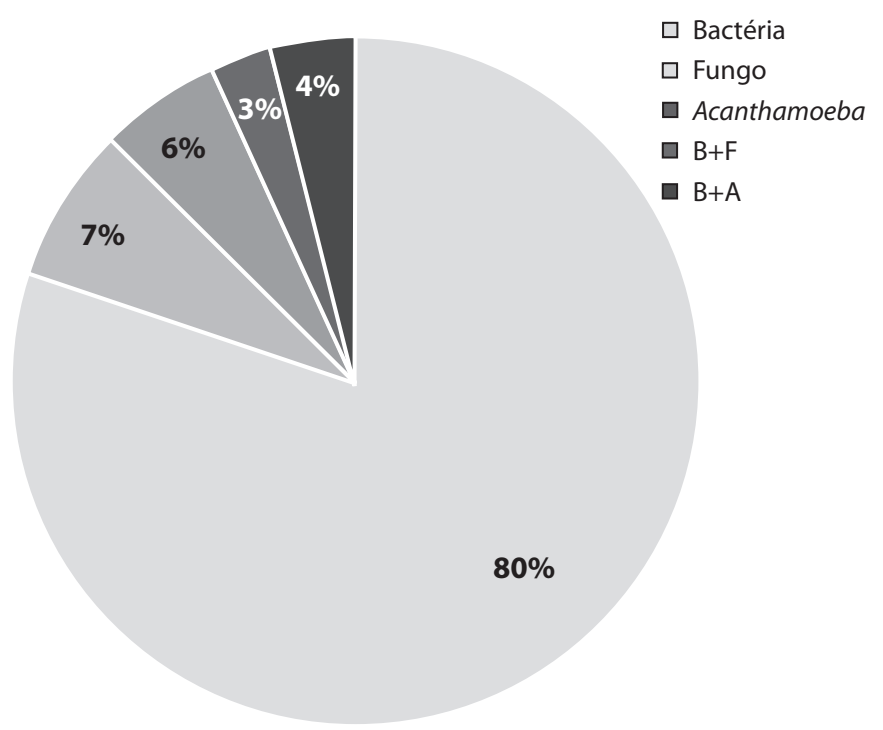

${ }^{*} \mathrm{~B}+\mathrm{F}=$ bactéria + fungo; $\mathrm{B}+\mathrm{A}=$ bactéria + Acanthamoeba.

Figura 1. Distribuição do total de ceratites infecciosas de 2005 a 2009.

Tabela 1. Número de casos de ceratite infecciosa por mês entre 2005 e 2009

\begin{tabular}{|c|c|c|c|c|c|c|c|c|c|c|c|c|c|}
\hline & Jan & Fev & Mar & Abr & Mai & Jun & Jul & Ago & Set & Out & Nov & Dez & Total \\
\hline Bactéria & 75 & 78 & 88 & 107 & 112 & 105 & 93 & 114 & 126 & 102 & 105 & 74 & 1.179 \\
\hline Fungo & 12 & 1 & 5 & 7 & 6 & 12 & 14 & 13 & 9 & 10 & 11 & 3 & 103 \\
\hline Acanthamoeba & 9 & 10 & 7 & 6 & 15 & 5 & 6 & 9 & 3 & 4 & 8 & 5 & 87 \\
\hline$B+F$ & 8 & 1 & 3 & 7 & 3 & 4 & 1 & 0 & 7 & 3 & 1 & 6 & 44 \\
\hline$B+A$ & 7 & 5 & 5 & 4 & 2 & 3 & 9 & 3 & 4 & 2 & 6 & 4 & 54 \\
\hline Total & 111 & 95 & 108 & 131 & 138 & 129 & 123 & 139 & 149 & 121 & 131 & 92 & 1.467 \\
\hline
\end{tabular}

$\mathrm{B}+\mathrm{F}=$ bactéria + fungo; $\mathrm{B}+\mathrm{A}=$ bactéria + Acanthamoeba . 
Tabela 2. Proporção dos agentes microbianos encontrados nas culturas

\begin{tabular}{|c|c|c|}
\hline Agente & $\mathbf{N}$ & $\%$ \\
\hline \multicolumn{3}{|l|}{ Bactérias } \\
\hline Staphylococcus sp & 770 & 51,7 \\
\hline Corynebacterium sp & 210 & 14,1 \\
\hline Streptococcus sp & 148 & 9,9 \\
\hline Pseudomonas sp & 94 & 6,3 \\
\hline Moraxella sp & 82 & 5,5 \\
\hline Serratia sp & 62 & 4,2 \\
\hline Enterobacter sp & 29 & 1,9 \\
\hline Citrobactersp & 21 & 1,4 \\
\hline Morganella sp & 11 & 0,7 \\
\hline Haemophilus sp & 9 & 0,6 \\
\hline Outros & 53 & 3,7 \\
\hline Total & 1.489 & 100,0 \\
\hline \multicolumn{3}{|l|}{ Fungos leveduriformes } \\
\hline Candidasp & 31 & 93,9 \\
\hline Rhodotorulasp & 2 & 6,1 \\
\hline Total & 33 & 100,0 \\
\hline \multicolumn{3}{|l|}{ Fungos filamentosos } \\
\hline Fusarium sp & 68 & 58,6 \\
\hline Paecilomyces sp & 10 & 8,6 \\
\hline Aspergillus sp & 9 & 7,8 \\
\hline Colletotrichum sp & 5 & 4,3 \\
\hline Scedosporium sp & 4 & 3,4 \\
\hline Outros & 20 & 17,3 \\
\hline Total & 116 & 100,0 \\
\hline
\end{tabular}

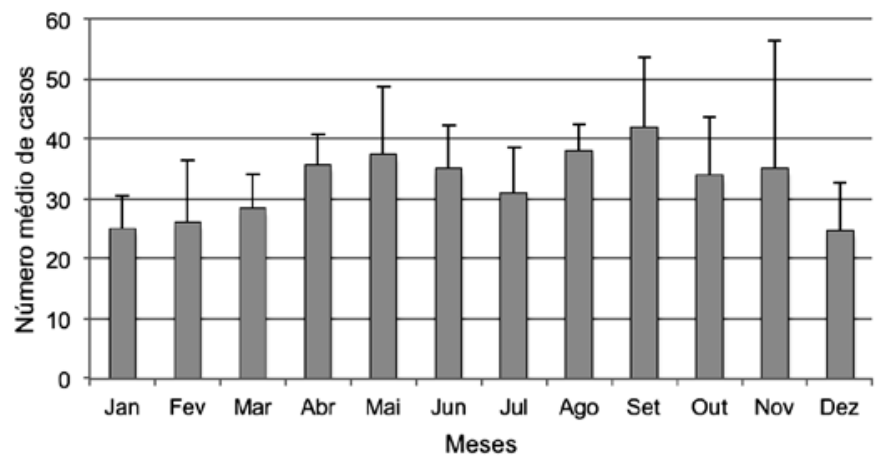

Figura 2. Distribuição mensal das ceratites infecciosas bacterianas de 2005 a 2009.

As ceratites infeciosas não mostraram variação importante ao longo do ano, estando sempre presentes em número razoavelmente constante.

Bharathi et al. mostraram associação entre maior número de casos de ceratite fúngica com clima úmido e quente do sudeste da Índia ${ }^{(11)}$. Na Austrália, Green et al. observaram frequência maior de ceratite fúngica e por Pseudomonas aeruginosa durante os meses mais quentes ${ }^{(12)}$. O Brasil não apresenta estações do ano tão definidas

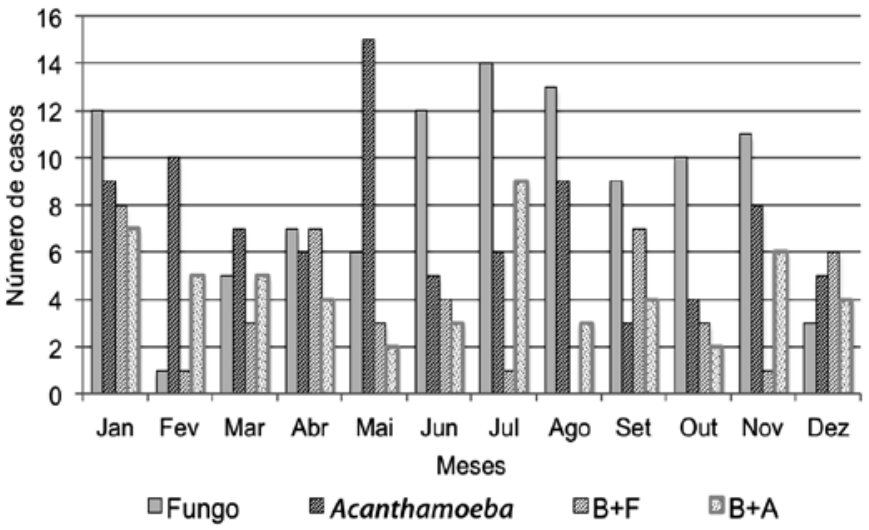

${ }^{*} \mathrm{~B}+\mathrm{F}=$ bactéria + fungo; $\mathrm{B}+\mathrm{A}=$ bactéria + Acanthamoeba.

Figura 3. Distribuição mensal das ceratites infecciosas não bacterianas de 2005 a 2009.

quanto em outros países como do hemisfério norte ou Índia onde estações chuvosas intercalam-se com estações mais secas.

Em um outro estudo indiano, Lin et al. analisaram a sazonalidade de diversos agentes infecciosos em ceratites. Observaram que os únicos agentes que apresentaram ciclos sazonais foram os fungos. Entretanto, os picos de frequência não foram coincidentes com os períodos de maior temperatura e umidade do ar e sim com o período de colheita dos agricultores juntamente com a época de ventos no sul da Índia. Neste estudo, não foram observados ciclos sazonais de agentes como bactérias ou Acanthamoeba ${ }^{(6)}$. Em um estudo de Ribeirão Preto (SP), Ibrahim et al. observaram aumento de casos de ceratites infecciosas, principalmente fúngicas entre os meses de maio e novembro, o que também coincide com o período de colheitas na região(13).

Não foi possível em nosso estudo estabelecer nenhum padrão de sazonalidade das ceratites infecciosas estudadas. Alguns dos possíveis motivos são a falta de estações do ano bem definidas, o fato do serviço da UNIFESP estar em grande centro urbano com pequena influência de variações da zona rural como época de colheitas e insuficiente número de casos para tal análise. Como limitações do estudo podemos citar o fato de ser retrospectivo o que não elimina presença de viés de informação e o fato de ser baseado em uma única instituição de referência excluindo casos diagnosticados e tratados em outros serviços.

Concluímos que não existe padrão de sazonalidade das ceratites infecciosas quando considerados dados do laboratório de microbiologia da UNIFESP. Valores de positividade de cultura e padrão das espécies encontradas durante o período de estudo concordam com outros publicados na literatura.

\section{REFERÊNCIAS}

1. Passos RM, Cariello AJ, Yu MC, Höfling-Lima AL. Microbial keratitis in the elderly: a 32-year review. Arq Bras Oftalmol. 2010;73(4):315-9.

2. Lima AL, Nishi M, Lottemberg CL, Guidugli T. Úlceras de córnea em serviço de referência. Arq Bras Oftalmol. 1988;51(3):118-20.

3. Upadhyay MP, Karmacharya PC, Koirala S, Shah DN, Shakya S, Shrestha JK, et al. The Bhaktapur eye study: ocular trauma and antibiotic prophylaxis for the prevention of corneal ulceration in Nepal. Br J Ophthalmol. 2001;85(4):388-92.

4. Erie JC, Nevitt MP, Hodge DO, Ballard DJ. Incidence of ulcerative keratitis in a defined population from 1950 through 1988. Arch Ophthalmol. 1993;111(12):1665-71.

5. Ormerod LD, Hertzmark E, Gomez DS, Stabiner RG, Schanzlin DJ, Smith RE. Epidemiology of microbial keratitis in southern California. A multivariate analysis. Ophthalmology. 1987;94(10):1322-33.

6. Lin CC, Lalitha P, Srinivasan M, Prajna NV, McLeod SD, Acharya NR, et al. Seasonal trends of microbial keratitis in South India. Cornea. 2012;31(10):1123-7.

7. Ibrahim MM, de Angelis R, Lima AS, Viana de Carvalho GD, Ibrahim FM, Malki LT, et al. A new method to predict the epidemiology of fungal keratitis by monitoring the sales distribution of antifungal eye drops in Brazil. PLoS One. 2012;7(3):e33775. 
8. Andrade AJ, Vieira LA, Höfling-Lima AL, Yu MC, Gompertz OF. Análise laboratorial de ceratites fúngicas em Serviço Universitário. Arq Bras Oftalmol. 2000;63(1):59-63.

9. Bourcier T, Thomas F, Borderie V, Chaumeil C, Laroche L. Bacterial keratitis: predisposing factors, clinical and microbiological review of 300 cases. Br J Ophthalmol. 2003;87(7):834-8. Comment in Br J Ophthalmol. 2003;87(7):805-6.

10. Gopinathan U, Sharma S, Garg P, Rao GN. Review of epidemiological features, microbiological diagnosis and treatment outcome of microbial keratitis: experience of over a decade. Indian J Ophthalmol. 2009;57(4):273-9.
11. Bharathi MJ, Ramakrishnan R, Meenakshi R, Padmavathy S, Shivakumar C, Srinivasan M. Microbial keratitis in South India: influence of risk factors, climate, and geographical variation. Ophthalmic Epidemiol. 2007;14(2):61-9.

12. Green M, Apel A, Stapleton F. A longitudinal study of trends in keratitis in Australia. Cornea. 2008:27(1):33-9.

13. Ibrahim MM, Vanini R, Ibrahim FM, Martins Wde P, Carvalho RT, Castro RS, et al. Epidemiology and medical prediction of microbial keratitis in southeast Brazil. Arq Bras Oftalmol. 2011;74(1):7-12

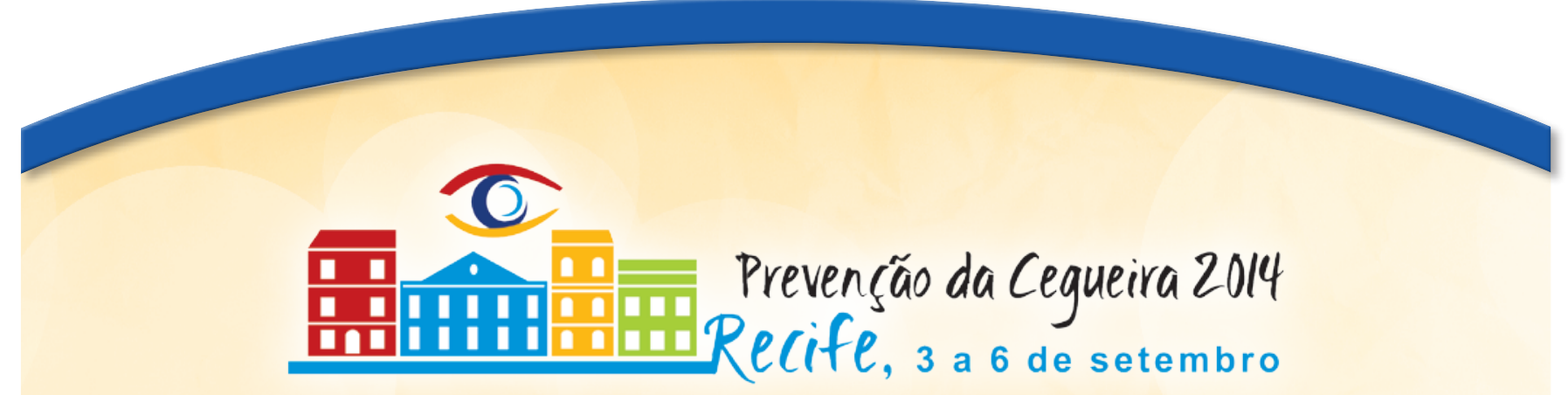

\section{Congresso Brasileiro de Prevenção da Cegueira e Reabilitação Visual \\ Il Congresso de Oftalmologia de Língua Portuguesa}

\section{3 a 6 de setembro de 2014}

\section{Centro de Convenções de Pernambuco}

Recife (PE)

\section{Informações:}

ASSESSOR - Assessoria e Marketing

Tels.: (81) 3423-1300 / 9172-7580

E-mail:comercial1@cbo2014.com.br

\section{MAIS Eventos}

Tels.: (81) 3033-5147 / 81 8129-4354

E-mail: comercial2@cbo2014.com.br

Site: http://www.congressocbo.com.br/cbo2014/ 